\title{
MARINE NATURAL PRODUCTS AND THEIR POTENTIAL APPLICATION IN THE FUTURE
}

\author{
Chau Van Minh", Phan Van Kiem, and Nguyen Hai Dang \\ Institute of Natural Products Chemistry, \\ Vietnamese Academy of Science and Technology \\ 18 Hoang Quoc Viet Road, Cau Giay, Hanoi, Vietnam
}

Received 04 November 2005

\section{INTRODUCTION}

Oceans are the diverse resource, which cover more than $70 \%$ of the earth's surface. No doubt, with 34 of 36 phyla of life represented, oceans are the greatest biodiversity in the world [1]. They are the extraordinary natural source of microorganism, algae, sponge, coelenterate, bryozoan, mollusk, and echinoderm... Especially, on coral reef, where shelter more than 1000 species per $\mathrm{m}^{2}$. Surprisingly, there is only a small number of researches in this field. Therefore increasing research on marine natural source may provide good results for exploiting and developing valuable natural products which benefit for human.

Marine environment is a rich source of biological and chemical diversity. The diversity has been unique source of chemical compounds of potential for pharmaceuticals, cosmetics, dietary supplements, and agrochemicals. Ecological pressure, including competitions for food and space, the fouling of predator and surface, has led to the evolution of secondary metabolites with various biological activities. Many organisms are soft bodies and/or unmoved, hardly survive with the threat from around environment. Hence they have evolved the ability to synthesize toxic compounds or obtain them from microorganism to defense against predator or to paralyze their prey. The questions such as, why do fish not eat particular algae? Why do two sponges grow and expand until they reach but not grow over each other? may be explained by these reasons.

For the past 30 - 40 years, marine invertebrates have been an attractive research topic for scientists all over the world. A small number of marine plants, animals, and microbes have yielded not less than 14000 natural products [2]. Of which, there are a lot of compounds showed potential pharmaceutical activities. Promisingly, some of them have been launched to the market and the others have been in clinical trials. In this review, we focus on marine natural products which have been targets in pharmaceutical industry, benefiting for human life as well as their potential applications in the future.

\section{MARINE NATURAL PRODUCTS AND THEIR POTENTIAL APPLICATIONS IN PHARMACEUTICAL INDUSTRY}

The researches on chemistry and biological activities of marine natural products have yielded many bioactive compounds showing various pharmaceutical properties. Many of which have

${ }^{*}$ Corresponding author e-mail: cvminh@vast.ac.vn 
been in clinical or in treatment of cancer, Alzheimer's, and infectious diseases. Moreover, they have also been used in the development of drugs for pain or cosmetics... All of these products are in preclinical and clinical trials except for the antiviral drugs Acyclovir and the antibiotic Cephalosporin, which are now in the market. Some of the others will be soon appeared in the drugs stores like ET-743 or Ziconotide. The mechanisms of action (MOA) and their uses will be described in the later sections.

\section{Marine natural products in clinical trials for treatment of cancer}

A number of marine natural products have been in clinical for antitumor activity since the early 1980s. The results obtained guaranteed for the potential application of these marine products in the near future. For the last decade, about 2.500 cytotoxic compounds have been reported, some of which are now in clinical trials for anticancer, such as dehydrodidemnin B, bryostatins, dolastatins...Currently, the mechanisms of action are being determined [3].

Didemnin B, a depsipeptide, was isolated from the tunicate Trididemnum sodium. This compound primarily showed potent antiviral, immunosuppressive, and cytotoxic activities [4, 5]. This compound was later advanced into clinical for various human diseases in the early $1990 \mathrm{~s}$, but because it was too toxic, the research on this agent was terminated $[6,7]$. In spite of its unsuccessful application, a number of its derivatives have been in clinical trials. Dehydrodidemnin B (APL) is a compound from Mediterranean tunicate discovered by Rinehart and coworker. The compound is in phase 2 studies for treatment of cancer in Europe and the USA. Surprisingly, it showed to be 6 times more effective than didemnin B in animal tests $[7,8]$.

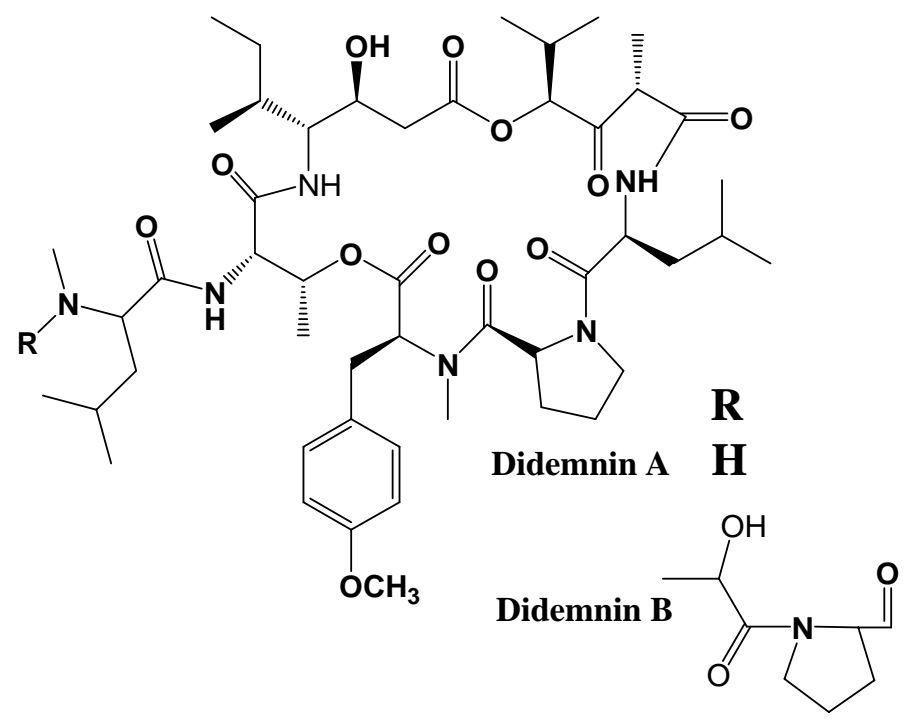<smiles>[2H]C[C@H](C)[C@H](C(=O)N[C@H](C(=O)N(C)[C@H]([C@H](C)CC)[C@@H](CC(=O)N1CCC[C@H]1[C@H](O)[C@@H](C)C(=O)N[C@H](Cc1ccccc1)c1nccs1)OC)C(C)C)N(C)C</smiles>

Dolastatin 10 
Dolastatin 10, a peptide of the mollusk Dolabella auricularia was isolated by Pettit et al. The clinical studies on this compound were terminated because of their less effective on anti prostate cancer $[8,9]$. However, the other dolastatins are still in clinical and preclinical trials, such as Synthadotin (ILX651), Soblidotin (TZT-1027), Cematodin (LU-102793)...TZT-1027 was found to strongly inhibit human lung cancer cell line. The dual effects on antivascular was also demonstrated. The recent studies found that TZT-1027 inhibits $85 \%$ growth of prostate carcinoma cell line in mouse models [10]. Another derivative of dolastatins is cematodin, this compound is currently in phase 1 and phase 2 of anti breast cancer [11 - 13]. Later, in 2001, the researchers of University of Hawaii were directly isolated dolastatin 10 from the symbiotic grazed on $D$. auricularia. This confirmed the hypothesis that dolastatins are originally produced by microbes.

Bryostatins are macrocyclic lactones isolated from the marine bryozoan Bugula neritica. Bryostatin 1 was one of the most promising anti cancer agents and the most abundant of this group. This compound was first known to inhibit the growth of murine P388 leukemia cells at subnanomolar concentrations [14]. Presently, there are more than 20 bryostatin derivatives have been reported [15]. The MOA of bryostatins were determined. These compounds are thought to bind to protein kinase $\mathrm{C}$ (PKC), a tumor promoting receptor. As a result, the PKC enzyme is significantly down-regulated, leading to inhibition of growth and cell death. More than 80 patients have been treated with bryostatin 1 in Europe and the USA [6]. However, the positive effects of bryostatin are obtained only when combined with other chemotherapies such as taxol and cisplatin. According to an independent research, Haygood and coworker demonstrated the hypothesis that bryostatins are symbiotic origin. Bryostatins were isolated from the symbiotic microbes (Candidatus Endobugula sertula) [16]. This interesting discovery leads to new approaches to solve the supply problem.
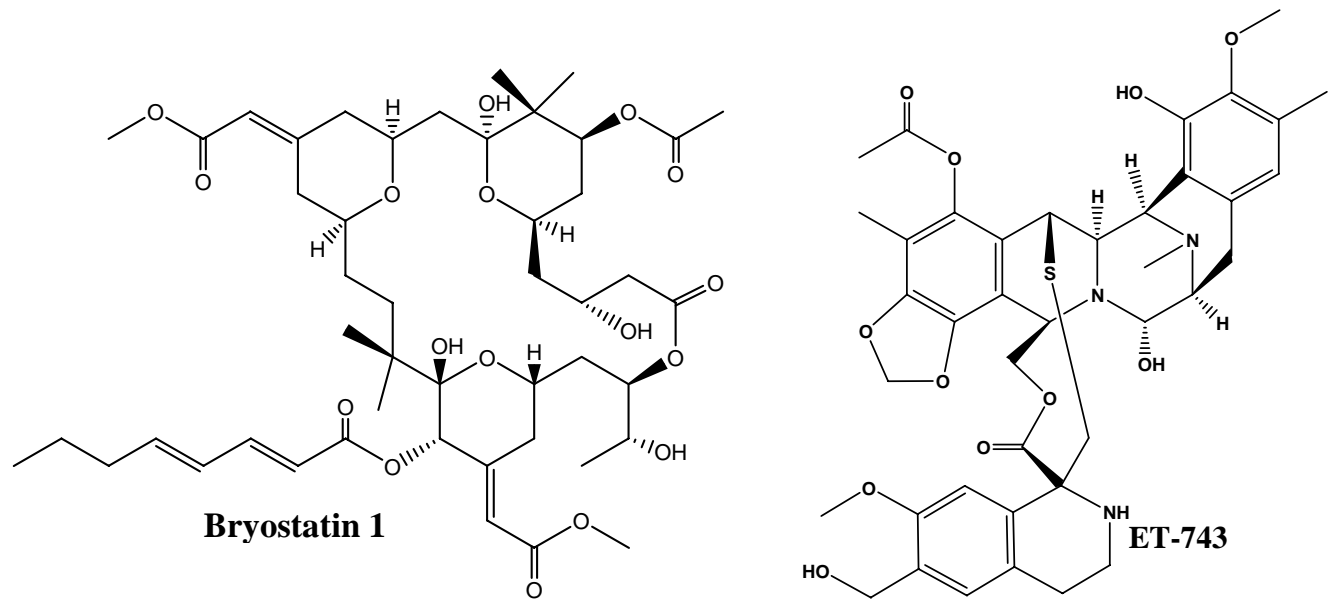

The antitumor effect of the ascidian Ecteinascidia turbinara was well known in 1969, but until the 1990s the major active component has been reported, Ecteinascidin 743 (ET-743) is a tetrahydroquinoline alkaloid originally identified in 1988 by Rinehart's team [18]. This is the DNA-interactive compound showing high potency of cytotoxic activity. Research on MOA demonstrated that ET-743 interfered with DNA repair pathway, changing in the DNA conformation [19]. This is the heart of unique action of this compound. Moreover, ET-743 inhibits the multidrug resistant of cancer cell lines with dororubixin and the others. The advanced research on MOA demonstrated its capacity on preventing P-glycoprotein formation, a protein associated with multidrug resistant tumors [20]. The studies on safety and dose usage have ensured its feasibility in treatment of soft-tissue sarcoma, breast cancer, and non-small cell lung cancer. Clinical trials of ET-743 are now being investigated in Europe and America with 
more than 1600 patients. Although it is not to be proven effective on it own, it may become a key ingredient of cocktail therapy in treatment of multidrug resistance tumors $[3,6,8,21]$.

Halichondrin B and its derivatives have been known as microtubule interfering agents. Halichondrin B was a polyester macrolide isolated from sponge Halichondria okadai. Currently, these compounds are in preclinical to determine their use in anti non-small lung cancer [22].

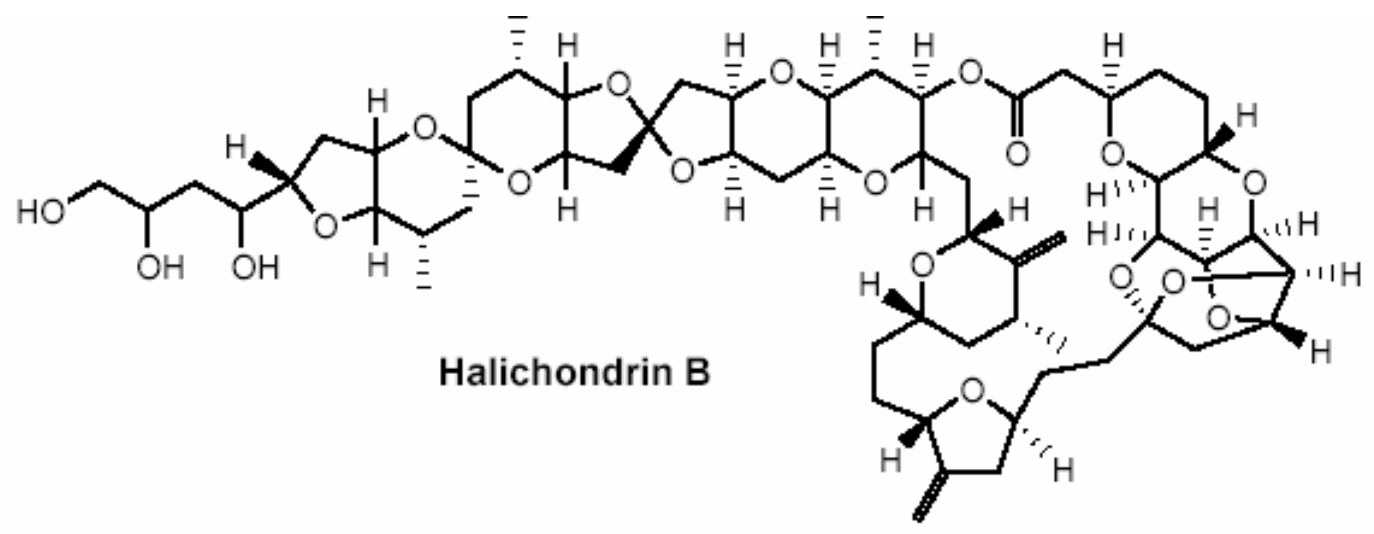

Kahalalide F, a cyclodepsipeptide isolated from sea slug Elysia rufescens, exhibited potent cytotoxic activities against prostate, breast and lung cancer cell lines [23]. According to recent researches, Kahalalide F disrupt lysosomal membrane resulting in formation of large vacuoles. This may simulate the initiation the process of apoptosis $[6,7]$. This compound is in the phase 2 clinical trials in patients with the prostate cancer and breast cancer.

The studies on the dogfish shark Squalus acanthias have revealed an anticancer compound. That is squalamine lactate, an aminosterol having significant anti angiogenesis activity. This compound is currently in phase 2 clinical trials for ovarian and non-small cell lung cancer $[2,6,7]$.
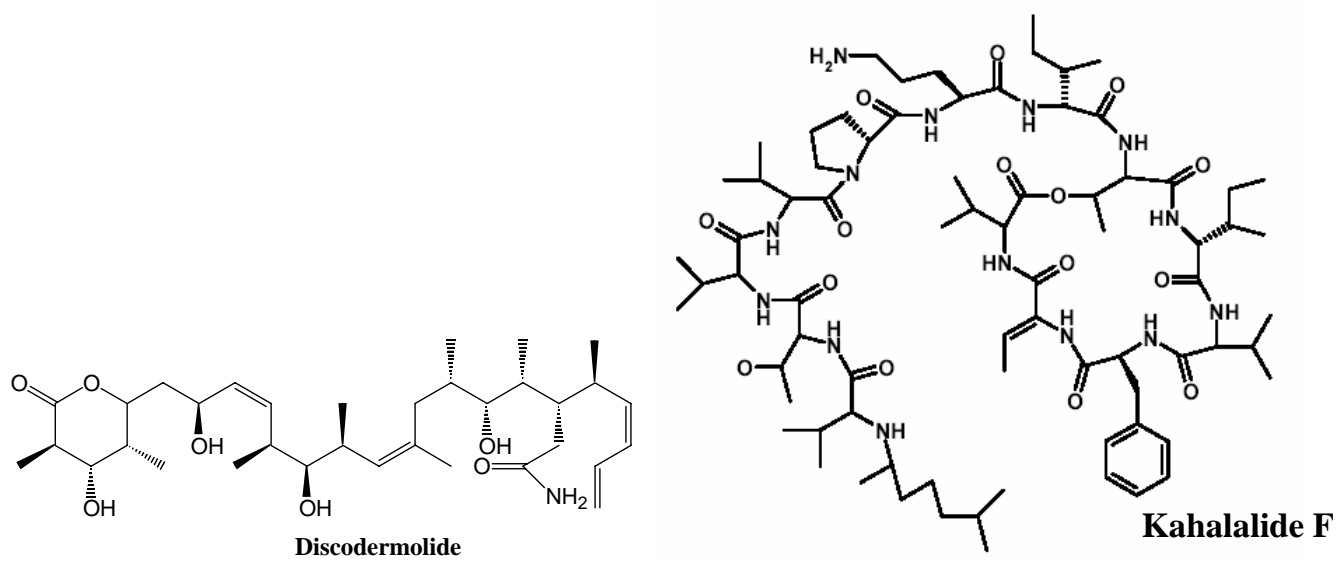

The other compounds have been known as anticancer agents for example Discodemolide, a compound isolated from the sponge Discodermiac dissoluta, has been known as immunosuppressive and cytotoxic agent [24]. Moreover, Spisulosine, HTI-286, KRN-7000, NVP-LAQ824, AE-941 [6, 21], Salinosporamide [25]... are the leads attracting for the researches worldwide by their potential uses as anticancer in the future. Notably, ET-743 will be formally launched to market in the year of 2005 as an anticancer drug. 


\section{Marine natural products and their application in antiinfectious diseases}

Infectious disease for centuries ranked with wars and famine as major challenges to human progress and survival. They remain to be one of the leading causes of death and disability in human. Although we have made many progresses in protecting our health, we can not avoid the periodically emerging of infectious diseases. Accordingly, the world today is facing with emergence of new epidemic threaten the human life (HIV-AIDS, SARS or bird flu by H5N1...) [26]. Study on the risk of emerging epidemic as well as finding new drugs for treating these diseases is one of the most interests for scientists today.

Oceans are rich source of biodiversity which hides a lot of antiinfective agents waiting for discovery. Nowadays, there are only a few pharmaceutical products in the market. Noteworthy, all of these products are antiinfectious drugs, for example: Cytarabine (Ara-C), an antiviral drug or cephalosporin, an antibiotic isolated from Cephalosporium sp [21, 27, 28]. The searches for marine natural products with high anti infectious activities are critical in many research centers.

There is a fact that marine organisms contain compounds different from terrestrial organisms by both structure and bioactivity. This led to the hypothesis in which marine organisms have potent antifungal compounds. These compounds may exert the activity with a mechanism different to man. Jasplakinolide is a cyclodepsipeptide isolated from the sponge Japis sp. This compound, also named Jaspamine, showed potent antifungal activities with MIC of $25 \mu \mathrm{g} / \mathrm{ml}$ against Candida albicans. This activity can be compared with miconazole [29]. The other effect of Jaspamine is anthemintic activity. This compound exhibits the nematocidal activity against Nippostrongylus braziliensis with $50 \%$ effective dose of less than $1.0 \mu \mathrm{g} / \mathrm{ml}$. Moreover, the antimalarial activity of this compound has been demonstrated by the year of $2002[1,30]$.

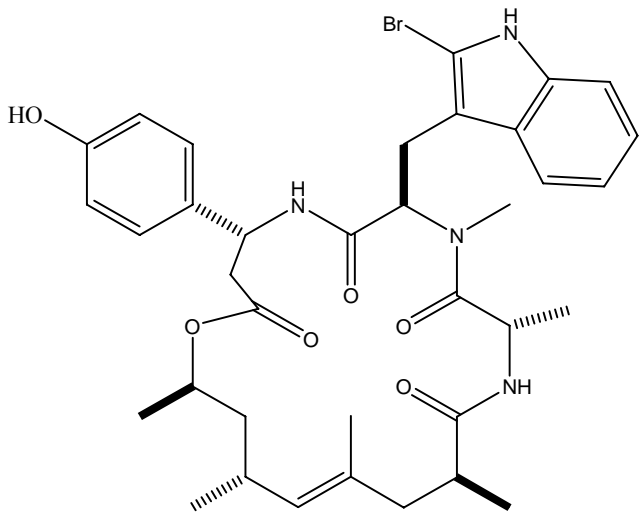

Jasplakinolide

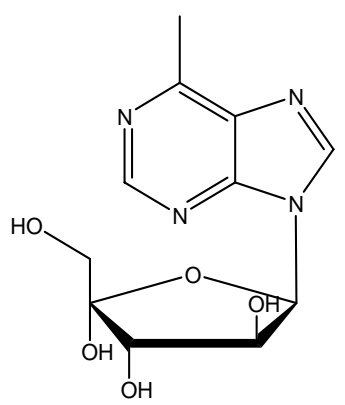

Ara- A<smiles>Nc1ccn(C2O[C@@H]3O[C@H]2CC3(O)CO)c(=O)n1</smiles>

Ara - C

The other antifungal agent is gambieric acid, a toxin isolated from Gambierdiscus toxicus. This compound has strong inhibition effect on Aspegillus niger at a concentration of $10 \mathrm{ng} / \mathrm{disk}$, which is 2000 times higher than Amphotericin B [31]. Notably, most of the antifungal compounds from marine origin have been shown cytotoxic activity, therefore it is difficult to advance these agents to clinical trials. The question whether antifungal activity out weighs cytotoxic effects should be considered.

Bacterial infective diseases are critical problem. The study on development of new antibiotic has been emerged recently. Turning out to research on marine natural products has revealed many pharmaceutical agents which high applicative potential. Once again, Squalamine was noted as a new bioactive compound. Squalamine is known not only for anticancer but also for 
antimicrobial agent (MIC of $1.0 \mu \mathrm{g} / \mathrm{ml}$ against Staphylococcus aureus) [32]. Cribrostatins were isolated from the sponge Cribrochalina sp, and showed antineoplastic and antimicrobial activity. The compounds also exhibited inhibition activity against penicillin resistant Neisseria. gonorrhea with MIC of $0.09 \mu \mathrm{g} / \mathrm{ml}$ [33 - 35]. From Atlantic ocean, an anti methicilin resistant S. aureus diterpenoid from Sphaerococcus cornopifolius were discovered, brommosphaerone, showing high minimum inhibitory concentration $(0.047 \mu \mathrm{g} / \mathrm{ml})[36]$.

In the other researches, Kazilauskas et al. isolated a new antibacterial alkaloid named N-metylat amide. However, this compound was later found to be too toxic for use [37]. Two new antimicrobial agents have been isolated from red alga, Laurencia elata and L. obtusa. They were determined as Elatol and Iso-obtusol. They exhibited considerable inhibitory activity against $S$. aureus, Klebsiella pneumonia, and Salmonella sp. The further studies on this compounds indicated that they have bacteriostatic rather than bacteriocidal activity $[38,39]$.<smiles>CC(C)[C@H](CC[C@@H](C)C1CC[C@H]2[C@@H]3[C@H](CC[C@]12C)[C@@]1(C)CC[C@@H](NCCCNCCCCN)C[C@@H]1C[C@H]3O)OS(=O)(=O)O</smiles>

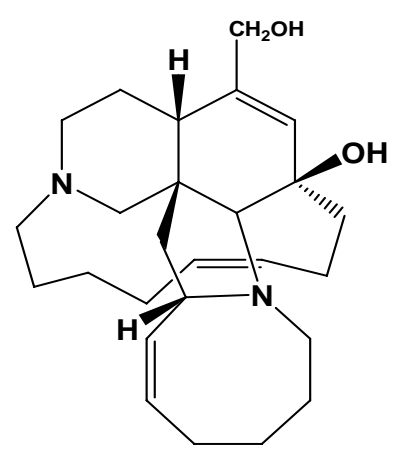

Ircinol A<smiles>COc1c(Cl)c(C)c(Cl)c(O)c1C(=O)c1c(O)cc(O)c(CC=C(C)C)c1C=O</smiles>

Pestalone

The recent advanced studies lead to the isolation of a potential antimicrobial compound, which is named pestalone. This compound inhibited S. aureus with MIC of $0.037 \mu \mathrm{g} / \mathrm{ml}$ and Enterococcus faecium with MIC of $0.078 \mu \mathrm{g} / \mathrm{ml}$. Noteworthy, pestalone was isolated from a marine fungus of the genus Pestalotia living on the surface of brown alga Rosenvingea sp [40]. The discovery led to the new method of producing this antibiotic by fermentation.

Besides the research on development of antibiotic, the search for new anti tuberculosis agents has become increasingly important with the emergence of multidrug resistant strain Mycobacterium tuberculosis. Although there are not many researches on marine natural products for antitubeculosis agents, the obtained results are considerable. (+)hydroxymanzamine, a heterocyclic alkaloid isolated from the sponge Pachypellina sp, showed potent inhibitory activity against $M$. tuberculosis $\mathrm{H} 37 \mathrm{Rv}$ with MIC of $0.91 \mu \mathrm{g} / \mathrm{ml}$ [41]. Another 
anti-tuberculosis compound, Ircinol A, is one of the most attractive agents. The compound did not show its toxic for cell and had a considerable MIC against $M$. tuberculosis, $1.93 \mu \mathrm{g} / \mathrm{ml}$. The other candidate is Puupehenone, which inhibited M. tuberculosis H3Rv with MIC of $2.0 \mu \mathrm{g} / \mathrm{ml}$ $[42,43]$.

Together with (+)hydroxymanzamine A, manzamine A was also isolated from Pachypellina sp. This compound is one of most promising agents for the development of anti-infectious diseases. Manzamine A had high inhibitory activities against multiple infective agents. This compound inhibited M. tuberculopsis with MIC of $1.56 \mu \mathrm{g} / \mathrm{ml}$ and Plasmodium falciparum with MIC of $0.0045 \mu \mathrm{g} / \mathrm{ml}$ [44]. This efficiency can be compared with the well known antimalaria drugs, artermisinin. Moreover, manzamine A prolongs $P$. berghei infected mice to more than 10 days, compared to 2 days when treated with artermisinin and 6 days when treated with chloroquine [1, 45]. Interestingly, several derivatives of manzamine have been discovered from an Indonesian sponge. These derivatives exhibited fairly high inhibitory activities against some infective agents. In 2003, the American research team demonstrated the direct production of manzamine A and hydroxymanzamine A by the cultivated commensal microbe Micromonospora sp [30, 46]. The result led to the potential application of these compounds for new anti-infective agents. Perhaps, this is one of the most important discoveries in the marine natural product researches in 2003.

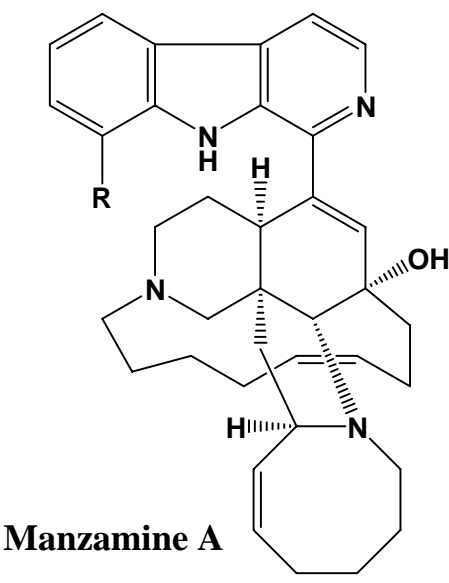<smiles>C#CC(O)/C=C/C=C/C=C/C#CC(O)C#CC/C=C/CC(O)C#C</smiles>

Polyacetylenetriol

Back in the 1950s, Bergmann et al. isolated several arabynosyl nucleosides from the Caribbean sponge Cryptotethia crypta. After that, several synthetic analogues have been formulated. Some of which, Ara-A, Ara-C, and Acyclovir became effective antiviral drugs available in the market $[25,47]$.

The search for antiviral agent has harvested numbers of positive results. From 2001 to 2002, six new compounds showing anti HIV and anti HSV activities have been isolated. Notably, polyacetylenetriol plays a vital role in inhibitory activity against retroviral reverse transcriptases. The authors noticed that ". . structural modification of the side chains of the lead polyacetylenic molecule may produce new potent and selective anti-AIDS drugs" [48].

\section{The other potential applications of marine natural products}

In 2002, some DPPH radical scavengers were isolated from the brown alga Cystoseira crinita. These compounds also exhibited high antioxidant activities in TBARS system. In which, some can be compared with the positive control BHT [49]. The search for antioxidant led to the discovery of superoxide scavenging compounds. In which, Aburatubolactams are the alkaloid isolated from marine bacteria Streptomyces sp. Superoxides are putative agents related to 
the future

cancer, inflammation, and aging. Therefore, inhibition of superoxide generation may prevent from these diseases. According to the reports, Aburatubolactams inhibit superoxide generation by neutrophils. The MOA are being determined [30].

Following to the efforts on seeking anti Alzheimer's disease, Kem et al. reported the purification of a hoplonemertine toxin, anabaseine. After that, a series of derivatives have been synthesized. DMXBA is the most important analogue. This derivative is well known with the name GTS-21 [50]. It showed good cytoprotective and memory enhancing effects, so GTS-21 can become a candidate for anti Alzheimer's and schizophrenia drug in the near future [6, 21]. GTS-21 is now in phase 1 clinical trial in Europe and America.<smiles>c1cncc(C2=NCCCC2)c1</smiles>

GTS-21

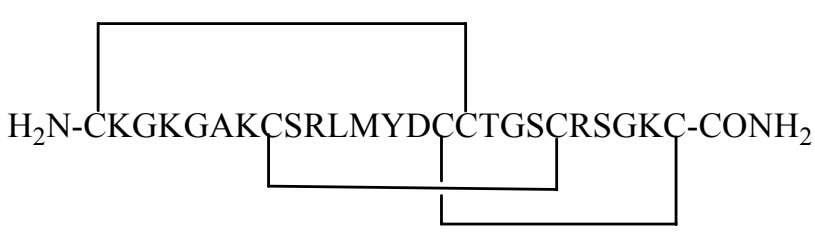

Ziconotide

Inflammation is the common disease, the anti-inflammatory drugs in the market today are mostly NSAIDs (non steroidal anti inflammatory drugs). These drugs act mainly on the mechanism of inhibitory key enzymes (the enzymes catalyze to the generation of inflammatory agents). For example: COX-1, COX-2 and 5-LOX are the enzymes catalyze to the generation of prostaglandin from arachidonic acid - an important agent in inflammation) or PLA $_{2}$ (Phospholipase $\mathrm{A}_{2}$ ) is the enzyme catalyzes for the generation of arachidonic acid...The first $\mathrm{PLA}_{2}$ inhibitor from natural products is manoalide, a sesterpene with $\mathrm{IC}_{50}$ of $3.9 \mu \mathrm{M}$. Manoalide was isolated from the sponge Luffatiella variabilis. Because of its potent anti-inflammatory and analgesic effects, this compound is now in phase 1 clinical trial. Although this agent is not clinically available, manoalide becomes a standard drug in inflammation research $[8,21,30,51$, 52]. The other $\mathrm{PLA}_{2}$ inhibitors are variabilin, cacospongiolide $\mathrm{B}$, bolinaquinone, and OAS1000 $[8,21,28]$.<smiles>CC=C(C)CCC1=C(C)CCCC1(C)C</smiles>

Manoalide<smiles>CCC1C=CC(C2=CC(=O)O[C@@H]2O)O[C@@H]1O</smiles>

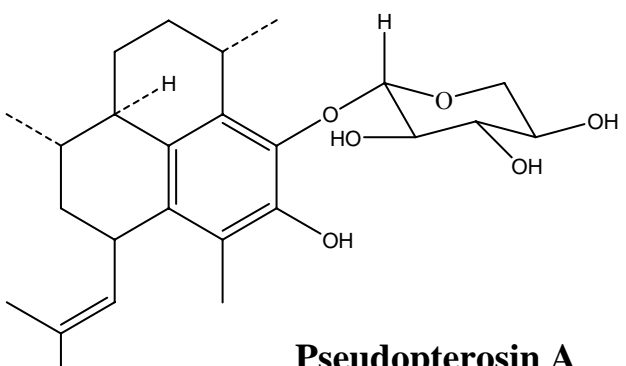

Another considerable anti-inflammatory agent is pseudopterosins. These compounds were isolated from the Caribbean sea whip Pseudopterogorgia elisabethae. They are potent antiinflammatory and analgesic agents and appear to inhibit eicosanoid biosynthesis by inhibition of both $\mathrm{PLA}_{2}$ and 5-lipoxygenase. One of pseudopterosins is now in clinical trial for antiinflammatory drug. Furthermore, pseudopterosins extract are available in the market as a cosmetic skin-care product $[6,53]$.

The consideration on exploiting marine natural product for agrochemical agent has been increasing recently. As we know, insects, weeds, and phytopathogenic fungi cause great damage to agriculture. The synthetic pesticides have been widely used in agriculture for long time. 
Nevertheless, the resistance to pesticides of insects and the negative effects on human health of these chemical agents led to the search for new natural agrochemical agents. Compared to the search for new pharmaceutical agents, little effort has been devoted to the exploration of agrochemicals from the sea. However, several marine natural products have been used as pesticides in some part of the world such as nereitoxin, bensultap, cartap, and thiocyclam derivatives [54]. According to Peng et al. the macrolides, polypeptides, and alkaloids are the promising agents for insecticidal, herbicidal, and fungicidal. These authors also noticed that manzamine $\mathrm{F}$ can be used as a new pesticide [55].

\section{MARINE TOXINS}

Study on marine toxins is one of important parts in marine natural product chemistry. The Japanese scientists are dominated in this field. Although there are larger and larger structures elucidated, polyester is considered the basic frame structure of marine toxins. In 1981, the 'ladder-like' skeleton was established by an X-ray crystallographic study, brevetoxin B isolated from Gymnodinium breve. After that, a series of brevetoxin derivatives have been isolated [52, 56]. Ciaguatoxin 2 is the major toxic component in marine food. This compound was isolated from Gambierdiscus javanicus in 1989 [57], but another ciguatoxin isolated from Gambierdiscus toxicus demonstrated the important role of food chain in seafood poisoning [58]. Herbivorous fish that feed on these organisms and carnivorous fish that eat the smaller herbivorous fish accumulate ciguatoxins and their metabolites. Ingestion of either type of fish can result in ciguatera. Ingestion of the major toxin, gambiertoxins (gambieric acid, gambierol...) can lead to the severe gastrointestinal symptoms (vomiting, diarrhea, and abdominal cramps), neurological sign (myalgia, paraesthesia, cold allodynia, and ataxia) [59].

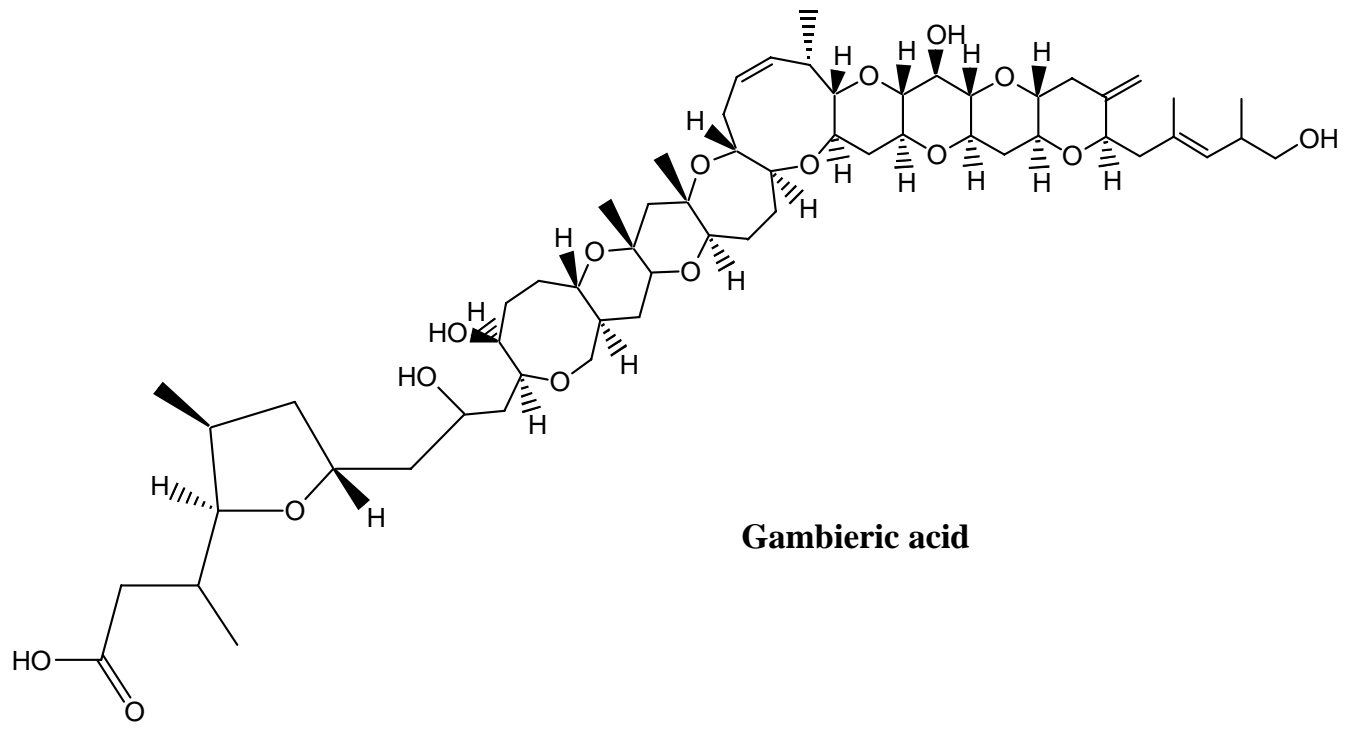

From the G. toxicus, a largest (except for biopolymers) and possibly the most lethal nonproteinaceous toxin, was identified. This compound, named maitotoxin, has molecular weight of 3422. The lethal dose $\left(\mathrm{LD}_{50}\right)$ to mice is $50 \mathrm{ng} / \mathrm{kg}$. However, this toxin may not contribute to food poisoning because of its low concentration and a poor absorption rate from digestive tracts $[60,61]$. The equal importance was also obtained from palytoxin, a complex structure isolated from Palythoa toxicus or tetrotoxin appeared in bony fishes $[6,60]$. The increasing frequency of 
toxic algal blooms and the associated shellfish contamination ensures that studies of marine toxins will continue to be of importance well into the next century, especially in food safety.

\section{MARINE NATURAL PRODUCT EXPLOITING, OPPORTUNITIES AND OBSTACLES}

One third of drugs in the market today are natural origin. Surprisingly, most of these drugs are from terrestrial. We live in a planet of oceans and the marine ecosystem covers more than $70 \%$ of the earth's surface. The consideration on exploiting marine source has been developed for the past 50 years. However, there are only a few marine natural products in the market. Until now, there are about 20 products in clinical trials. Most of them are for treatment of cancer, pain, and infectious diseases. So what are the difficulties and obstacles for exploiting of these resources? What are the future trends for the development of marine natural products?

Marine organisms possess physicochemical properties related to various bioprocesses including protect themselves from the predators, infections and competitions. Living in such a harsh environment, marine organisms produced the components with unique structures. Pharmaceutically, many of them are cytotoxic, as a result, most of marine products exhibit anticancer activities. The research on marine natural products today focuses on invertebrates (sponges, mollusks, and echinoderms). In contrast, marine algae are not proven to be a rich producer of bioactive compounds.

One important fact to develop marine natural products is supply problem. Perhaps this is the most important factor challenging the development of products from the sea. Indeed, in order to obtain $1 \mathrm{~g}$ of ET-743, close to 1 metric tone (wet weight) of E. turbinata have to be collected and extracted. For halichondrin B, it does seem to be more difficult to obtain enough amounts: 1 metric tone (wet weight) of the sponge (Lissodendoryx sp) yield $300 \mathrm{mg}$ of mixture of two halichondrins. Consequently, the application in clinical is impossible because of the low productivity of these compounds. For example, provided that halichondrins will at one time launch for treatment of cancer, it is estimated that $1-5 \mathrm{~kg}$ of halichondrin will be consumed annually. Therefore, 3,000 - 16,000 tones of Lissodendoryx sp have to be collected and extracted for a year [2]. Clearly, natural exploiting will never be completed. The exploiting can destruct the ecosystem of the sea.

Synthesis marine bioactive compounds is the other method. However, the structures of some compounds are extremely complex, the synthesis, in many case, is not feasible. PharmaMar, a Spanish pharmaceutical company, have efforts to synthesize ET-743 from the marine Pseudomonas fluorescens metabolite. The 21- step synthesis revealed successfully. This was feasible despite a low overall yield of $1.4 \%$ because the starting material could be obtained on a large scale by fermentation [6]. The synthesis processes of the other bioactive agents such as halichondrin B, bryostatins, gambierol, APL, KF...have harvested positive results in spite of low yield. The most impressive marine natural product synthesis is MVIIA (Ziconotide). This peptide can be obtained virtually unlimited amounts through synthesis $[2,6,62,63]$.

The other ability to exploit natural products is marine culture. By culturing B. neritica, the American scientists have obtained large amounts of bryostatin 1 . Subsequently, bryostatin 1 was produced in sufficient quantities at a reasonable cost [64].

Recently, there is larger evidence provided that the compounds isolated from invertebrates are microbial origin. For instance, Jaspakinolide, a compound isolated from the sponge Japis sp. Later, from the bacteria Chondromyces crocatus, a similarity has been isolated. It named chondramine D. The structural study on ET-743 led to the identification of a congener named safracin B from P. fluorescens. Symbostatin 1, a similar skeleton to dolastatin 10 was isolated from the green alga Symploca hydnoides. The similarity can be explained by the hypothesis that 
many marine invertebrates are filter feeders that ingest bacteria or the other small particles from inhaled sea water. It is possible that some bioactive compounds can be produced by microorganism and invertebrates take up them from food chain. Typically, bryostatin 1, as mentioned above, is actually produced by a symbiotic microorganism living in the host bryozoan $[2,6,65,66]$. The speculation suggested to the new method for the development of marine natural products. Accordingly, fermentation seems to be one of the best choices for marine natural product chemistry to reach the industrial production.

\section{CONCLUSIONS}

The search for "drug from the sea" has been received intense interests for recent years. The simplistic analysis of data revealed that the rate of discovery of new compound have achieved 10 percent every year. In which, many bioactive compounds have been identified. According to data obtained, sponges, coelenterates, and microorganisms are always the dominated source of new compounds. Anticancer and anti-infectious diseases are the major bioactivities reported. Furthermore, tunicates, echinoderms and sponges are the main sources for these activities because they contain a lot of unexplored bioactive compounds.

The efforts of seeking for anticancer agents from the sea have been concentrated on sponges, microorganism, tunicates, and mollusks. On the other hand, the searches for analgesic, antibiotic, and anti-inflammatory compounds have been received notable results. From the scientific studies, some pharmaceutical agents have been launched to the market (Ara-A, Ara-C, Pseudoterosin...), the others have been in final states of clinical trials (ET-743, Kahalalide F, Ziconotide...). Besides the achievements, marine natural product chemistry faces up to many difficulties. For example, the limited supply or the large scale exploitation can destroy the environment. Hopefully, synthesis and fermentation may be the major methods for the development of this field. Clearly, oceans will be major contributors for the discovery of useful products for human life in the foreseeable future.

\section{REFERENCES}

1. Donia, M. and Hamann, M.T. (2003), Marine Natural Products and Their Potential Applications as Anti-infective Agents, The Lancet Infect. Dis., vol. 3, pp. 338-348.

2. Proksch, P., Edrada-ebel, R., and Ebel, R. (2003), Drugs from the Sea - Opportunities and Obstacles, Mar. Drugs, vol. 1, pp. 5-17.

3. Jimeno, J., Faircloth, G., Sousa-Faro, J.M.F., Scheuer, P., and Rinehart, K. (2004), New Marine Derived Anticancer Therapeutics - A Journey from the Sea to Clinical Trials, Mar. Drugs, vol. 2, pp. 14-29.

4. Rinehart, K., Gloer, J.B., and Cook, J.C. (1981), J. Am. Chem. Soc., vol. 103, pp. $1857-$ 1859.

5 Rinehart, K.L., Kishore, V., Bible, K.C., Sakai, R., Sullins, D.W., and Li, K.M. (1988), Didemnins and Tunichlorin: Novel Natural Products from the Marine Tunicate Trididemnum solidum. J. Nat. Prod., vol. 51, pp. 1-21.

6. Newman, D.J., and Cragg, G.M. (2004), Marine Natural Products and Related Compounds in Clinical and Advanced Preclinical Trials, J. Nat. Prod.,vol. 67, pp. 12161238.

7. Jha, R.K. and Zi-rong, X. (2004), Biomedical Compounds from Marine Orangisms, Mar. Drugs, vol. 2, pp. 123-146. 
8. Kijjoa, A. and Sawangwong, P. (2004), Drugs and Cosmetics from the Sea, Mar. Drugs, vol. 2, pp. 73-82.

9. Pettit, G. R. (1997), The Dolastatins, Prog. Chem. Org.Nat. Prod., vol. 70, 307.

10. Bhaskar, V., Law, D.A., Ibsen, E., Breinberg, D., Cass, K.M., DuBridge, R.B., Evangelista, F., Henshall, S.M., Hevezi, P., Miller, J.C., Pong, M., Powers, R., Senter, P., Stockett, D., Sutherland, R.L., von Freeden-Jeffry, U., Willhite, D., Murray, R., Afar, D.E.H., and Ramakrishnan, V. (2003), E-selectin Up-Regulation Allows for Targeted Drug Delivery in Prostate Cancer, Cancer Res., vol. 63, pp. 6387-6394.

11. Smyth, J., Boneterre, M.E., Schellens, J.H.M., Calvert, H., Greim, G., Wanders, J., and Hanauske, A. (2001), Activity of the Dolastatin Analogue, LU103793, in Malignant Melanoma, Ann. Oncol., vol.12, pp. 509-511.

12. Kerbrat, P., Dieras, V., Pavlidis, N., Ravaud, A., Wanders, J., and Fumoleau, P. (2003), Phase II Study of LU 103793 (Dolastatin Analogue) in Patients with Metastatic Breast Cancer, Eur. J. Cancer, vol. 39, pp. 317-320.

13. Marks, R.S., Graham, D.L., Sloan, J.A., Hillman, S., and Fishkoff, S. (2003), A Phase II Study of the Dolastatin 15 Analogue LU 103793 in the Treatment of Advanced NonSmall-Cell Lung Cancer, Am. J. Clin. Oncol., vol. 26, pp. 336-337.

14. de Vries, D.J. and Beart, P.M. (1995), Fishing for Drugs from the Sea: Status and Strategies, TiPS, vol. 16, pp. 275-279.

15. Wender, P.A., Hinkle, K.W., Koehler, M.F.T., and Lippa, B. (1999), The Rational Design of Potential Chemotherapeutic Agents: Synthesis of Bryostatin Analogues, Med. Res. Rev., vol. 19, pp. 388-407.

16. Davidson, S. K., Allen, S. W., Lim, G. E., Anderson, C. M., and Haygood, M. G. (2001), Evidence for the biosynthesis of bryostatins by the bacterial symbiont "Candidatus Endobugula sertula" of the bryozoan Bugula neritina, Appl. Environ. Microbiol., vol. 67, pp. 4531-4537.

17. Sigel, M. M., Wellham, L. L., Lichter, W., Dudeck, L. E., Gargus, J., and Lucas, A. H. (1969), In: Food-Drugs from the Sea Proceedings, Younghen, H. W., Jr., (Eds.), Marine Technology Society: Washington, DC, pp. 281-294.

18. Wright, A. E., Forleo, D. A., Gunawardana, G. P., Gunasekera, S. P., and Koehn, F. E. (1990), McConnell, O. J., J. Org. Chem., vol. 55, pp. 4508-4512.

19. Takebayashi, Y. et al., (2001), Antiproliferative Activity of Ecteinascidin 743 is Dependent Upon Transcription-coupled Nucleotide Excision Repair, Nat. Med., vol. 7, pp. 961-966.

20. Zewail-Foote, M. and Hurley, L. H. (1999), Ecteinascidin 743: A Minor Groove Alkylator that Binds DNA Toward the Major Groove, J. Med. Chem., vol. 42, pp. 24932497.

21. Haefner, B. (2003), Drugs from the Deep: Marine Natural Products as Drug Candidates, DDT, vol. 8, pp. 536-544.

22. Bai, R. L. et al, (1991), Halichondrin B and homohalichondrin B, marine natural products binding in the vinca domain of tubulin. Discovery of tubulin-based mechanism of action by analysis of differential cytotoxicity data, J. Biol. Chem., vol. 266, pp. 15882-15889.

23. Hamann, M. T. and Scheuer, P. J. (1993), Kahalide F; A Bioactive Depsipeptide from the Sacoglossan Mollusk Elisia refescens and the Green Alga Bryopsis sp., J. Am. Chem. Soc., vol. 115, pp. 5825-5826.

24. Gunasekera, S. P., Gunasekera, M., Longley R. E., and Schulte, G. K. (1990), J. Org. 
Chem., vol. 55, pp. 4912-4915.

25. Blunt, J.W., Copp, B.R., Munro, M.H.G., Northcote, P.T., and Prinsep, M.R. (2005), Marine Natural Products, Nat. Prod. Rep., vol. 22, pp. 15-61.

26. Morens, D.M., Folkers, G.K., and Fauci, A.S. (2004), The Challenge of Emerging and Re-emerging Infectious Diseases, Nature, vol. 430, pp. 242-249.

27. Kelecom, A. (2002), Secondary Metabolites from Marine Microorganisms, An. Acad. Bras. Cienc., vol. 74, pp. 151-170.

28. Bugni, T.S. and Ireland, C.M. (2004), Marine-derived Fungi: a Chemically and Biologically Diverse Group of Microorganisms, Nat. Prod. Rep., vol. 21, pp. 143-163.

29. Crews, P., Manes, LV., and Boehler, M. (1986), Jasplakinolide a cyclodepsipeptidefrom the marine sponge Jaspis sp. Tetrahedron Lett., vol. 27, pp. 2797-800.

30. Mayer, A.M.S. and Hamann, M.T. (2005), Marine pharmacology in 2001-2002: Marine compounds with anthelmintic, antibacterial, anticoagulant, antidiabetic, antifungal, antiinflammatory, antimalarial, antiplatelet, antiprotozoal, antituberculosis, and antiviral activities; affecting the cardiovascular, immune and nervous systems and other miscellaneous mechanisms of action, Comp. Biochem. Phys., Part C 2005, vol. 140, 265-286.

31. Nagai, H., Murata, M., Torigoe, K., Satake, M., and Yasumoto, T. (1992), Gambieric acids: new potent antifungal substances with unprecedented polyether structures from a marine dinoflagellate Gambierdiscus toxicus, J. Org. Chem.,vol. 57, pp. 5448-5453.

32. Rao, M.N., Shinnar, A.E., and Noecker, L.A., et al. (2000), Aminosterols from the dogfish shark Squalus acanthias, J. Nat. Prod., vol. 63, pp. 631-635.

33. Pettit, R.K., Fakoury, B.R., Knight, J.C., Weber, C.A., Pettit, G.R., Cage, G.D., and Pon, S. (2004), Antibacterial activity of the marine sponge constituent cribrostatin 6, J. Med. Microbiol., vol. 53, pp. 61-65.

34. Pettit, G.R., Knight, J.C., Collins, J.C., Herald, D.L., Pettit, R.K., Boyd, M.R., and Young, V.G. (2000), Antineoplastic agents 430. Isolation and structure of cribrostatins 3, 4, and 5 from the Republic of Maldives Cribrochalina species, J. Nat. Prod., vol. 63, pp. 793-798.

35. Pettit, G.R., Collins, J.C., Knight, J.C., Herald, D.L., Nieman, R.A., Williams, M.D., and Pettit, R.K. (2000), Antineoplastic agents 485. Isolation and structure of cribrostatin 6, a dark blue cancer cell growth inhibitor from the marine sponge Cribrochalina sp, J. Nat. Prod., vol. 66, pp. 544-547.

36. Etahiri, S., Bultel-Ponce, V., Caux, C., and Guyot, M. (2001), New bromoditerpenes from the red alga Sphaerococcus coronopifolius, J. Nat. Prod., vol. 64, pp. 1024-1027.

37. Krebs, H.C. (1986), Recent Development in the Field of Marine Natural Products with Emphasis on Biological Active Compounds, Fortschr. Chem. Org. Naturst., vol. 49, pp. 151-363.

38. Sims, J.J., Lin, G.H.Y., Wing, and R.M. (1974), Tetrahedron Lett., vol. 39, 3487.

39. Vairappan, C.S. (2003), Potent antibacterial activity of halogenated metabolites from Malaysian red algae Laurencia majuscula (Rhodomelaceae, Ceramiales), Biomol. Eng., vol. 20, pp. 255-259.

40. Cueto, M., Jensen, P.R., Kauffman, C., Fenical, W., Lobkovsky, E., and Clardy, J. (2001), Pestalone a new antibiotic produced by a marine fungus in response to bacterial 
challenge, J. Nat. Prod., vol. 64, pp. 1444-1446.

41. Yousaf, M., El-Sayed, K.A., Rao, K.V., et al. (2002), 1234-oxamanzamines Novel Biocatalytic and Natural Products from Manzamine Producing Indo-Pacific Sponges, Tetrahedron,vol. 58, pp. 7397-7402.

42. Faulkner, D.J. (1999), Marine Natural Products, Nat. Prod. Rep., vol. 16, pp. 155-198.

43. Nasu, S.S., Yeung, B.K.S., Hamann, M.T., Scheuer, P.J., Kelly-Borges, M., and Goins, K.D. (1995), Puupehenone-related metabolites from two Hawaiian sponges Hyrtios spp, J. Org. Chem., vol. 60, pp. 7290-7292.

44. Ang, K.K.H., Holmes, M.J., Higa, T., Hamann, M.T., and Kara, U.A. (2000), In vivo antimalarial activity of the $\beta$-carboline alkaloid manzamine A. Antimicrob, Agents Chemother, vol. 44, pp. 1645-1649.

45. El-Sayed, K.A., Kelly, M., Kara, U.A.K., et al. (2001), New manzamine alkaloids with potent activity against infectious diseases, J. Am. Chem. Soc., vol. 123, pp. 1804-1808.

46. Wright, A.D., Konig, G., Angerhofer, C.K., Greeidge, P., and Faóndez, R.D. (1996), The Search for Marine Derived Natural Products with Selective Antimalarial Activity, J. Nat. Prod., vol. 59, pp. 710-716.

47. Scheuer, P.J. (1996), Marine Metabolites as Drug Leads-Retrospect and Prospect, In: Biochemica Aspects of Marine Pharmacology.l Alaken, Inc.: Fort Collins, Colorado, pp. 1-12.

48. Loya, S., Rudi, A., Kashman, Y., and Hizi, A. (2002), Mode of inhibition of HIV-1 reverse transcriptase by polyacetylenetriol, a novel inhibitor of RNA- and DNA-directed DNA polymerases, Biochem. J., vol. 362, pp. 685-692.

49. Fisch, K.M., Bohm, V., Wright, A.D., and Konig, G.M. (2003), Antioxidative meroterpenoids from the brown alga Cystoseira crinita, J. Nat. Prod., vol. 66, pp. 968-975.

50. Kem, W.R., Abbott, B.C., and Coates, R.M. (1971), Toxicon, vol. 9, pp. 15-22.

51. Kuramoto, M., Arimoto, H., and Uemura, D. (2004), Bioactive Alkaloids from the Sea, Mar. Drugs, vol. 1, pp. 39-54.

52. Faulkner, D.J. (2000), Highlights of Marine Natural Products Chemistry, Nat. Prod. Rep., vol. 17, pp. 1-6.

53. Rouhi, A.M. (1995), Supply Issues Complicate Trek of Chemicals from the Sea to Market, C\&EN, vol. 20, pp. 42-44.

54. Llewellyn, L.E. and Burnell, J.N. (2000), Marine organism as sources of C4-weedspecific herbicides, Pestic. Outlook, pp. 64-67.

55. Peng, J., Shen, X., El-Sayed, K.A., Dunbar, C.D., Perry, T.L., Wilkins, S.P., and Hamann, M.T. (2003), Marine Natural Products as Prototype Agrochemical Agents, J. Agric. Food Chem., vol. 51, pp. 2246-2252.

56. Baden, D.G., Bourdelais, A.J., Jacocks, H., Michellira, S., and Naar, J. (2005), Natural and Devivative Brevetoxins Historical Background, Multiplicity and Effects, Environmetal Heath Perspectives, vol. 113, pp. 621-625.

57. Murata, M., A. Legrand, M., Ishibashi, Y., Fukui, M., and Yasumoto, T. (1990), J. Am. Chem. Soc., vol. 112, 4380. 
58. Yasumoto, T., and Murata, M. (1993), Chem. Rev., vol. 93, 1897.

59. Isbister, G.K. and Kiernan, M.C. (2005), Neurotoxic Marine Poisoning, The Lancet Neurol., vol. 4, pp. 229-238.

60. Daly, J.W. (2004), Marine Toxins and Nonmarine Toxins: Convergence or Symbiotic Organisms, J. Nat. Prod., vol. 67, pp. 1211-1215.

61. Yashumoto, T. (2005), Chemistry, Etiology, and Food Chain Dynamics of Marine Toxins, Proc. Japan Acad., vol. 81, pp. 43-51.

62. Nicholas, G.M. and Phillips, A.J. (2005), Marine Natural Products: Synthetic Aspects, Nat. Prod. Rep., vol. 22, pp. 144-161.

63. Faulkner, D.J. (2001), Marine Natural Products, Nat. Prod. Rep., vol. 18, pp. 1-49.

64. Mendola, D. (2000), Aquacultural Production of Bryostatin 1 and Ecteinascidin 743, In: Drugs from the sea, pp. 120-133.

65. Harada, K. (2004), Production of Secondary Metabolites by Freshwater Cyanobacteria, Chem. Pharm. Bull.,vol. 52, pp. 889-899.

66. Konig, G.M. and Wright, A.D. (1996), Marine Natural Products Research: Current Directions and Future Potential, Planta Med., vol. 62, pp. 193-211. 